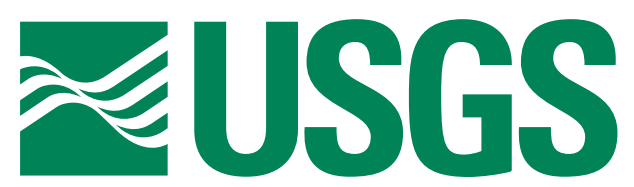

\title{
A Reconnaissance for Sulfonylurea Herbicides in Waters of the Midwestern USA: An Example of Collaboration Between the Public and Private Sectors
}

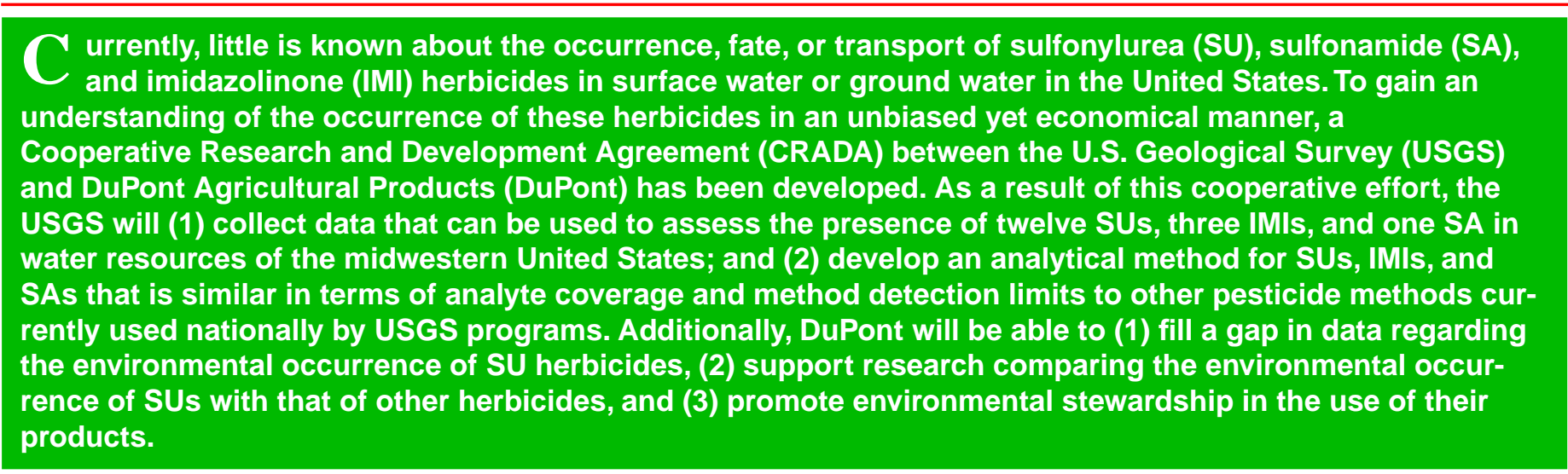

\section{BACKGROUND}

Over the last 20 years, a generation of low application rate herbicides have been developed that act by inhibiting the action of a key plant enzyme, resulting in stopped growth and eventual plant death. The enzyme that these herbicides act upon is specific to plants and they are reported to have very low toxicities in mammals or other animals (Brown, 1990; Meister, 1997). SU, SA, and IMI herbicides are three compound classes that act in this manner. Crops that can be treated with SUs, SAs, and IMIs include barley, corn, cotton, durum wheat, peanuts, rice, soybeans, sugar beets, canola, spring wheat, and winter wheat. These herbicides are gaining in popularity among farmers. The total corn, soybean, and wheat acreage on which 9 SUs, 1 SA and 2 IMIs were applied in eleven midwestern States (Iowa, Illinois, Indiana, Kansas, Kentucky, Minnesota, Missouri, Nebraska, Ohio, South Dakota, and Wisconsin) from 1990 through 1996 is shown in figure 1 (U.S. Department of Agriculture, 1991-97). In 1996, the area treated exceeded 59 million acres. For comparison, atrazine, a triazine herbicide, was used on 44.2 million acres of corn in the same 11-State area, in 1996. Although applied over comparable areas, SU, SA, and IMI herbicides typically are applied at much lower rates than other commonly used herbicides classes. For example, in 1996, in the same 11-State midwestern area, an estimated 23,200 tons of atrazine and 19,360 tons of metolachlor were applied to cropland, while the estimated use of 9 SUs, 1 SA, and 2 IMIs was only 1,150 tons (U.S. Department of Agriculture, 1997).

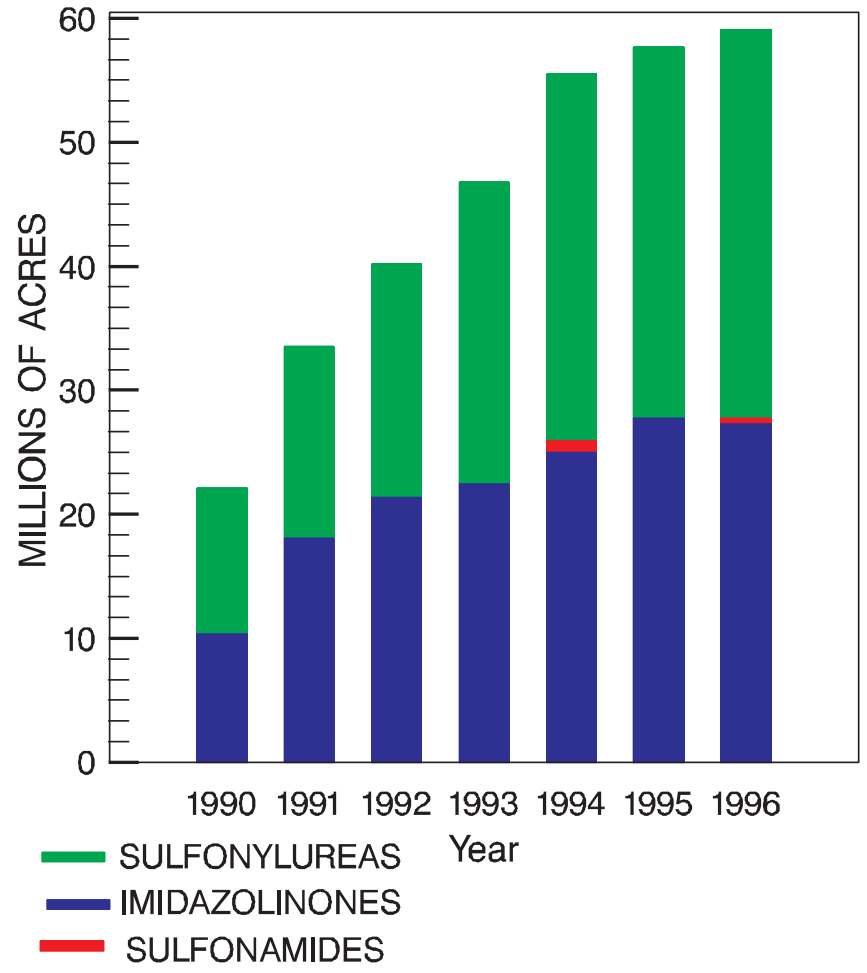

Figure 1. Estimated acres of corn, soybeans, or wheat treated with selected sulfonylurea, sulfonamide, and imidazolinone herbicides, 1990-96, in midwestern States.

Plants demonstrate a wide range in sensitivity to SUs, SAs, and IMIs with over a 1000-fold difference in observed toxicity levels for some compounds. The concentration in water in the soil zone is the toxicologically 
relevant concentration. Because SUs, SAs, and IMIs are active at very low concentrations they can cause a problem with plant vigor in some crop rotations even when only 1 percent or less of the originally applied material remains. Little non-target crop stress is expected from soil water concentrations below $0.1 \mu \mathrm{g} / \mathrm{L}$ (micrograms per liter, or part per billion). Less is known about the effect of these compounds on noncrop plant species, but a concentration of $1.0 \mu \mathrm{g} / \mathrm{L}$ in water appears to be a threshold for possible native aquatic plant toxicity (U.S. Environmental Protection Agency, Office of Pesticide Programs, Environmental Fate and Effects Division, Tox One-Liner Database, written commun., 1997).

Table 1. Common names, chemical classes, trade names, and crops treated for target analytes

\begin{tabular}{|c|c|c|c|}
\hline Common name & Class & Trade names $^{1}$ & Crops treated \\
\hline bensulfuron methyl & sulfonylurea & Londax & rice \\
\hline chlorimuron ethyl & sulfonylurea & Classic, Canopy, Reliance & soybeans, peanuts \\
\hline chlorsulfuron & sulfonylurea & Glean, Telar, Finesse & grains, non-crop land \\
\hline flumetsulam & sulfonamide & Broadstrike, Preside, Scorpion & corn, soybeans \\
\hline halosulfuron methyl & sulfonylurea & Battalion, Manage, Permit & corn, sorghum, turf \\
\hline imazapyr & imidazolinone & Arsenal, Chopper & noncropland \\
\hline imazaquin & imidazolinone & Scepter, Detail & soybeans \\
\hline imazethapyr & imidazolinone & Pursuit & soybeans, corn \\
\hline metsulfuron methyl & sulfonylurea & Allie, Ally, Escort & grains, pasture, noncrop \\
\hline nicosulfuron & sulfonylurea & Accent & corn \\
\hline primisulfuron methyl & sulfonylurea & Beacon, Tell & corn \\
\hline prosulfuron & sulfonylurea & Peak & corn, sorghum, grains \\
\hline sulfometuron methyl & sulfonylurea & Oust & trees, noncrop, turf \\
\hline thifensulfuron methyl & sulfonylurea & Pinnacle, Reliance & soybeans, grains, corn \\
\hline triasulfuron & sulfonylurea & Amber, Longran & grain, fallow \\
\hline triflusulfuron methyl & sulfonylurea & Upbeet & sugarbeets \\
\hline
\end{tabular}

\section{WHAT IS A CRADA?}

Cooperative Research and Development Agreements or CRADAs were created by the Federal Technology Transfer Act of 1986. The Act permits CRADAs to be developed by Federal agencies to encourage collaboration with non-Federal parties. CRADAs enable both partners to share intellectual material, protect information, and leverage their research budgets to optimize results. The non-federal partner can provide services, personnel, equipment, or funds in order to accomplish the goals of the CRADA. The Federal partner can provide similar resources but not funds directly to the partner. CRADAs typically consist of two components: general provisions (the legal framework) and a statement of work (the objectives, tasks, and deliverables of the CRADA activity). A CRADA is a legal contract forming a business agreement. Unlike the typical contract for procured services regulated by Federal Acquisition Regulations, a CRADA between Federal and private sector partners is a type of noncompetitive agreement. More details about CRADAs can be found on the USGS Technology Transfer homepage (see http://www.usgs.gov/tech-transfer/index.html).

\section{SPECIFICS ABOUT THE USGS-DUPONT CRADA}

The CRADA between the USGS and DuPont consists of general provision (10 pages), and a statement of work (approximately 12 pages). Development, review, and approval of the CRADA by both parties took about 6 months. While CRADA use in some Federal agencies

such as the U.S. Environmental Protection Agency has been extensive, the CRADA between the Water Resources Division of the USGS and DuPont is one of the first to be developed between the USGS and a non-federal partner. The overall objective of the CRADA is to begin developing an understanding of the occurrence of selected SUs, SAs, and IMIs in water resources of the midwestern United States.

The CRADA outlines tasks and products that are expected from both parties. The tasks listed as DuPont's responsibilities under the CRADA include (1) providing the USGS National Water Quality Laboratory (NWQL) with the written materials and guidance needed to develop and validate an analytical method for detecting selected SUs, SAs, and IMIs in water samples at a quantification limit of $0.1 \mu \mathrm{g} / \mathrm{L}$, (2) providing technical consultation to the NWQL on analytical methods adaptation and development, and (3) providing data on the physical and chemical properties and toxicity of SUs and their degradation products. The tasks listed as USGS responsibilities include (1) developing and executing a work plan for the first year of the project focusing on sample collection (with samples going to a laboratory chosen by DuPont) and analytical methods development, (2) validating the performance of the analytical method provided by DuPont as part of an Association of Official Analytical Chemists (AOAC) method validation process, (3) modifying the DuPont method, if feasible, to improve sensitivity to a 
point were it is comparable with the sensitivity of other analytical methods currently offered by the NWQL for other classes of pesticides and to include other labile pesticide parent compounds and degradation products of SUs, SAs, and IMIs, (4) developing a work plan for 1998 focusing on a multi-state intensive reconnaissance to determine the frequency and magnitude of SU, SA, and IMI detections in water samples, and (5) publishing reports that interpret the results from samples collected and analyzed by the USGS in 1998.

The CRADA also outlines any constraints or limitations that are placed on the information exchanged, results obtained, or data generated by the CRADA activity. The subject CRADA specifies that the USGS and DuPont will be allowed to freely publish the results of this study within the limitations of section 7.4.2 (a section of the General Provisions). This section states that the USGS and DuPont agree to confer and consult at least 30 days prior to either party's submission for publication of subject data. The CRADA also states that the USGS and DuPont will be allowed to review and comment upon, but not censor any data, interpretations, or reports resulting from the CRADA activity. For publication purposes, data generated from samples analyzed by the NWQL will be reported as USGS data and data generated by analyses by DuPont or by any laboratory selected by Dupont will not be reported as USGS data.

External oversight and technical review of analytical methods development, work plan development, study design, and data interpretations are provided by the Interagency Method and Data Comparability Board (MDCB). The MDCB and the National Water-Quality Monitoring Council (NWQMC) were chartered in 1997 under the Federal Advisory Committee Act. The Council's charge is to implement a nationwide strategy to improve waterquality monitoring, assessment, and reporting, and to oversee activities of the MDCB. The Board's charge is to identify, examine, and recommend monitoring approaches that facilitate collaboration and yield comparable data and assessment results. Board members come from Federal, State, tribal, and private organizations and have a mix of interests and expertise. Oversight by the MDCB of the activities associated with this CRADA provides an external review by a group with diverse perspectives.

The USGS will commit time and personnel for work plan development, analytical methods development, sample collection, sample analysis, data interpretation, and reports preparation. DuPont will commit time and personnel for analytical methods development support, sample analysis, reviews of work plans, and reviews of data interpretations. DuPont will also commit financial support for sample collection and analysis, for a portion of analytical methods development, and for some costs associated with the external oversight (travel and meeting costs).

\section{Project Status \\ Analytical Methods}

A multianalyte water method developed by DuPont is one of five methods developed in association with the EPA/Industry Multianalyte Methods (MAM) group. The DuPont method (Rodriguez and Orescan, 1996) uses electrospray HPLC/MS (high performance liquid chromatography coupled with mass spectrometry) to detect 16 SUs, SAs, and IMIs (table 1) with a limit of quantitation of $0.1 \mu \mathrm{g} / \mathrm{L}$ for all analytes. NWQL Methods Development staff have started on an Association of Official Analytical Chemists (AOAC) validation for the DuPont method. Further method development work has also started. The goal is to modify the DuPont method, to improve sensitivity to a point were it is comparable with the sensitivity of methods for other classes of pesticides (method reporting limits range from 0.001 to $0.05 \mu \mathrm{g} / \mathrm{L}$ ). The NWQL has targeted several activities that are expected to help improve the sensitivity of this method. These include (1) switching from external standard quantitation to internal standard quantitation, (2) increasing the sample size for extraction from 250 milliliters to 1 liter, (3) comparing a range of extraction media, and (4) expanding the range of analytes to include additional SU, SA, and IMI herbicides and herbicide metabolites.

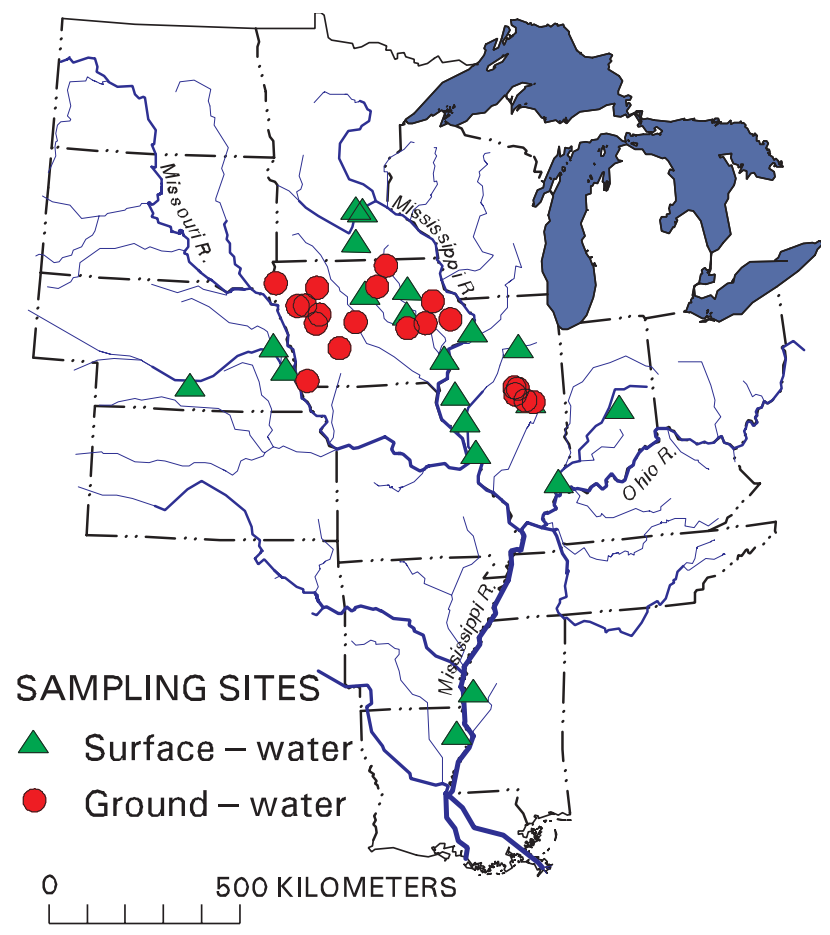

Figure 2. Location of surface-water and ground-water sites sampled in 1997. 

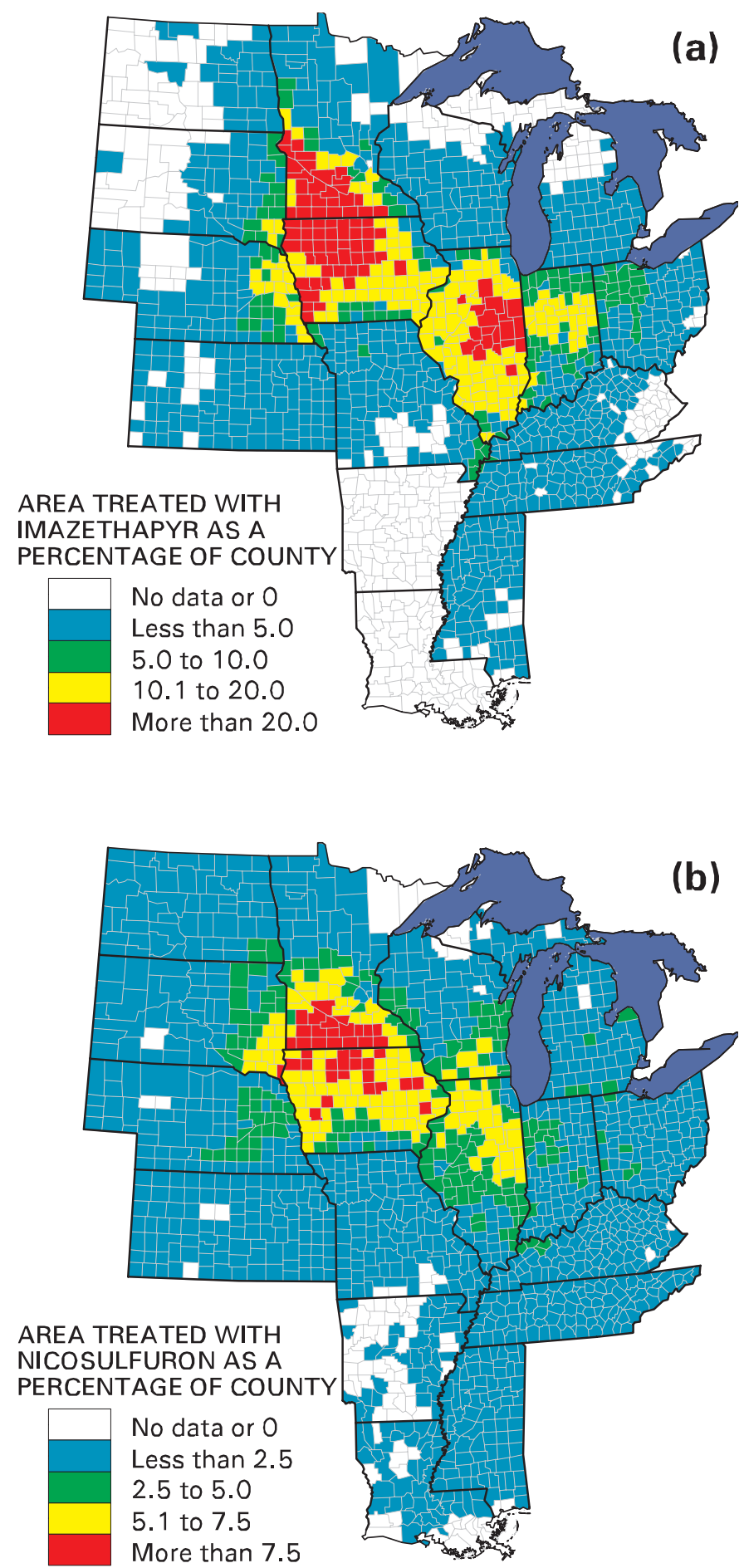

Figure 3. Estimated 1992 county-level use of (a) imazethapyr and (b) nicosulfuron.

\section{Sample Collection}

The first phase of CRADA sampling activity was initiated in summer and fall 1997. Approximately 50 samples were collected by USGS personnel from 40 sites (20 streams and 20 wells) (fig. 2). These samples were sent to researchers at the National Soil Tilth Laboratory (chosen by DuPont) for analysis. Sampling activities in 1998 will focus in the areas of highest herbicide use (fig. 3). The 1998 study plan calls for the collection of
150-200 samples from 100 sites. These samples will be analyzed at the NWQL using both the DuPont method and the modified method for at least the 16 analytes listed in table 1 plus any additional herbicides or herbicide degradation products added to the target analytes list by the method modifications. Water from all or selected samples collected in 1998 will be sent to DuPont for confirmatory analysis. Water from all samples collected in 1998 will also be analyzed for selected other pesticides. Where possible, samples will be collected in conjunction with planned USGS activities in order to reduce sample collection costs.

\section{Expected Results}

The expected outcome of the activities associated with this CRADA will be a better understanding the occurrence of selected SU, SA, and IMI herbicides in water resources of the midwestern United States. Specific results will include AOAC validation of DuPont's multianalyte water method for selected SUs, SAs, IMIs and development of a modified method with improved sensitivity. Analytical results and interpretations from water samples collected and analyzed by the USGS in a 1998 will be published. This CRADA is also expected to serve as an example of how cooperative projects with the USGS and private industry enables leveraging of budgets and optimization of results while maintaining an impartial scientific approach to addressing nationally relevant earth science questions.

\section{—By William A. Battaglin, Edward T. Furlong, and C. John Peter}

\section{REFERENCES}

Brown, H.M., 1990, Mode of action, crop selectivity, and soil relations of the sulfonylurea herbicides: Pesticide Science. vol. 29, p. 263-281.

Meister, R.T., 1997, Farm chemicals handbook'97: Willoughby, Ohio, Meister Publishing.

Rodriguez, M. and Orescan, D.B., 1996, Analytical method for the quantitation and confirmation of selected sulfonylurea, imidazolinone, and sulfonamide herbicides in surface water using electrospray LC/MS: DuPont Report No. AMR 4118-96.

U.S. Department of Agriculture, 1991-1997, Agricultural chemical usage-1990-1996 field crops summary: Washington, D.C., USDA, National Agricultural Statistics Service, (published annually).

For further information, contact:

William A. Battaglin

U.S. Geological Survey

Box 25046, MS 406, Denver Federal Center

Denver, CO 80225 